\title{
Modulation of Amyloidogenic Protein Self-Assembly Using Tethered Small Molecules
}

\author{
Emma E. Cawood, Nicolas Guthertz, Jessica S. Ebo, Theodoros K. Karamanos, Sheena E. Radford,* \\ and Andrew J. Wilson*
}

Cite This: J. Am. Chem. Soc. 2020, 142, 20845-20854

Read Online

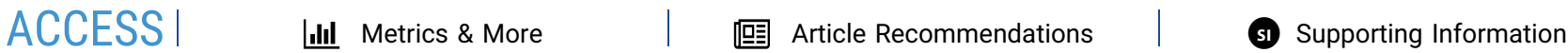

ABSTRACT: Protein-protein interactions (PPIs) are involved in many of life's essential biological functions yet are also an underlying cause of several human diseases, including amyloidosis. The modulation of PPIs presents opportunities to gain mechanistic insights into amyloid assembly, particularly through the use of methods which can trap specific intermediates for detailed study. Such information can also provide a starting point for drug discovery. Here, we demonstrate that covalently tethered small molecule fragments can be used to stabilize

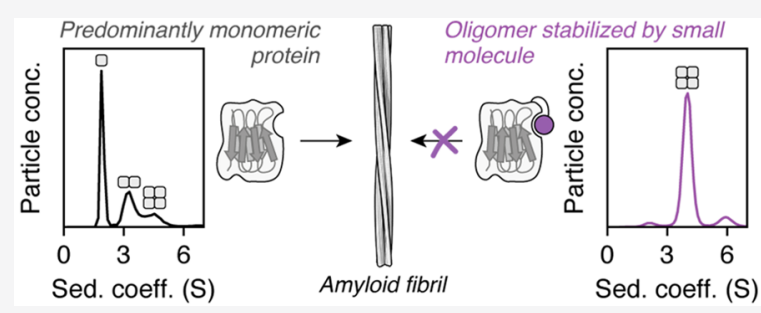
specific oligomers during amyloid fibril formation, facilitating the structural characterization of these assembly intermediates. We exemplify the power of covalent tethering using the naturally occurring truncated variant $(\Delta \mathrm{N} 6)$ of the human protein $\beta_{2}$-microglobulin $\left(\beta_{2} \mathrm{~m}\right)$, which assembles into amyloid fibrils associated with dialysis-related amyloidosis. Using this approach, we have trapped tetramers formed by $\Delta \mathrm{N} 6$ under conditions which would normally lead to fibril formation and found that the degree of tetramer stabilization depends on the site of the covalent tether and the nature of the protein-fragment interaction. The covalent protein-ligand linkage enabled structural characterization of these trapped, off-pathway oligomers using X-ray crystallography and NMR, providing insight into why tetramer stabilization inhibits amyloid assembly. Our findings highlight the power of "post-translational chemical modification" as a tool to study biological molecular mechanisms.

\section{INTRODUCTION}

The regulated self-assembly of proteins into ordered complexes drives many biological processes, ranging from viral capsid formation and actin polymerization, to DNA maintenance and repair. ${ }^{1,2}$ However, self-assembly can also occur aberrantly as a result of changes in the concentration, ${ }^{3}$ environment, ${ }^{4-6}$ primary sequence, ${ }^{7,8}$ or post-translational processing ${ }^{9-11}$ of a protein. Aberrant assembly events are associated with a range of disorders, and they can involve polymerization of natively folded protein molecules, ${ }^{2}$ as in sickle cell anemia, ${ }^{12}$ or aggregation which is accompanied by significant conformational changes, as exemplified by amyloid diseases. ${ }^{13,14}$ Understanding the molecular basis and consequences of such protein-protein interaction (PPI) pathways and identifying methods for their modulation ${ }^{15-20}$ therefore have implications for the treatment of disease, ${ }^{21}$ as well as in the development of new biomaterials, where protein self-assembly can be exploited to yield structures with defined architectures or novel biomechanical properties. $^{22,23}$ However, manipulating and defining the mechanisms of self-assembly is challenging, due to the transient nature and heterogeneity (in mass and structure) of oligomeric intermediates. ${ }^{24,25}$ The use of methods to trap specific oligomeric complexes can help overcome these challenges and offers the opportunity to structurally characterize otherwise transient intermediates, identify targets for drug discovery, and develop new scaffolds for protein-based nanostructures.

Here, we describe the use of disulfide tethering ${ }^{26}$ to rapidly explore chemical space and identify "post-translational chemical modifications"27,28 that stabilize specific PPIs associated with amyloid assembly. These site-specific, covalent modifications may act in one of two ways: altering the surface properties of the protein and/or covalently reinforcing a noncovalent protein-ligand interaction. Using a naturally occurring, amyloidogenic variant of $\beta_{2}$-microglobulin $\left(\beta_{2} \mathrm{~m}\right)-$ the $\Delta$ N6 variant-as a model system, we show that covalently tethered fragments represent highly effective tools for tuning oligomer populations and stabilizing particular species in selfassembly pathways. By combining kinetic analysis with structural information obtained from NMR and X-ray crystallography, the covalent modifications identified here have led to structural and functional insights into the role of tetramers in $\Delta \mathrm{N} 6$ amyloid formation.

Received: October 6, 2020

Published: November 30, 2020 


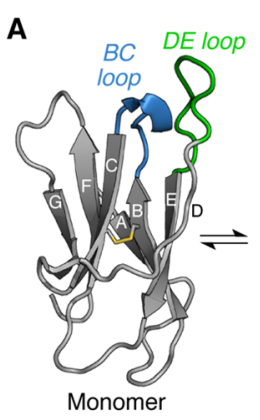

A

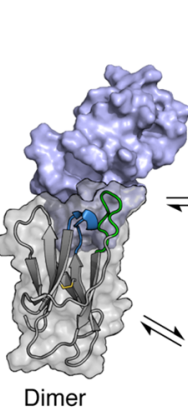

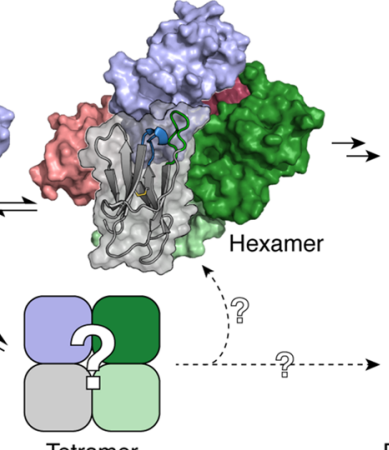

Tetramer

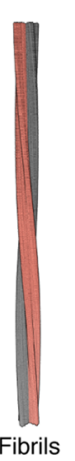

B

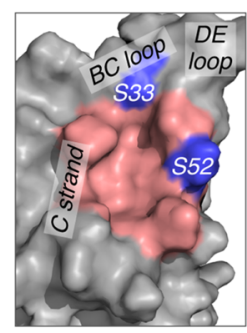

Target site 1

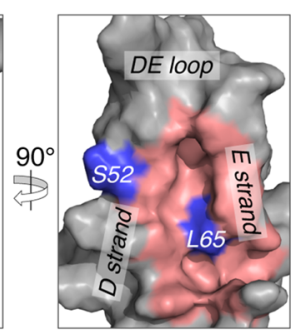

Target site 2

Figure 1. (A) Native monomeric $\Delta \mathrm{N} 6\left(\mathrm{PDB} 2 \mathrm{XKU}^{36}\right.$ ) contains seven antiparallel $\beta$-strands (labeled A-G), with a solvent-excluded disulfide bond between strands $\mathrm{B}$ and $\mathrm{F}$ (yellow). The monomeric protein is capable of associating into transient, nativelike dimers and hexamers en route to amyloid fibrils (structures not drawn to scale). ${ }^{37}$ The conversion of these nativelike oligomers into fibrils requires structural rearrangement of the existing $\beta$-strands ${ }^{38}$ and further self-assembly. $\Delta \mathrm{N} 6$ tetramers have been observed, but their structure and role in fibril formation depend on the solution conditions. ${ }^{37,39}$ (B) The two most ligandable sites (pink) of $\Delta$ N6 identified by computational solvent mapping are located adjacent to the BC (target site 1) and DE (target site 2) loops. Three residues (S33, S52, and L65; purple) at these two sites were substituted with cysteine in order to target each pocket using the disulfide tethering strategy (see Figure $2 \mathrm{~A}$ ). The orientation of $\Delta \mathrm{N} 6$ in the "Target site 1" panel is the same as for the monomer shown in (A).
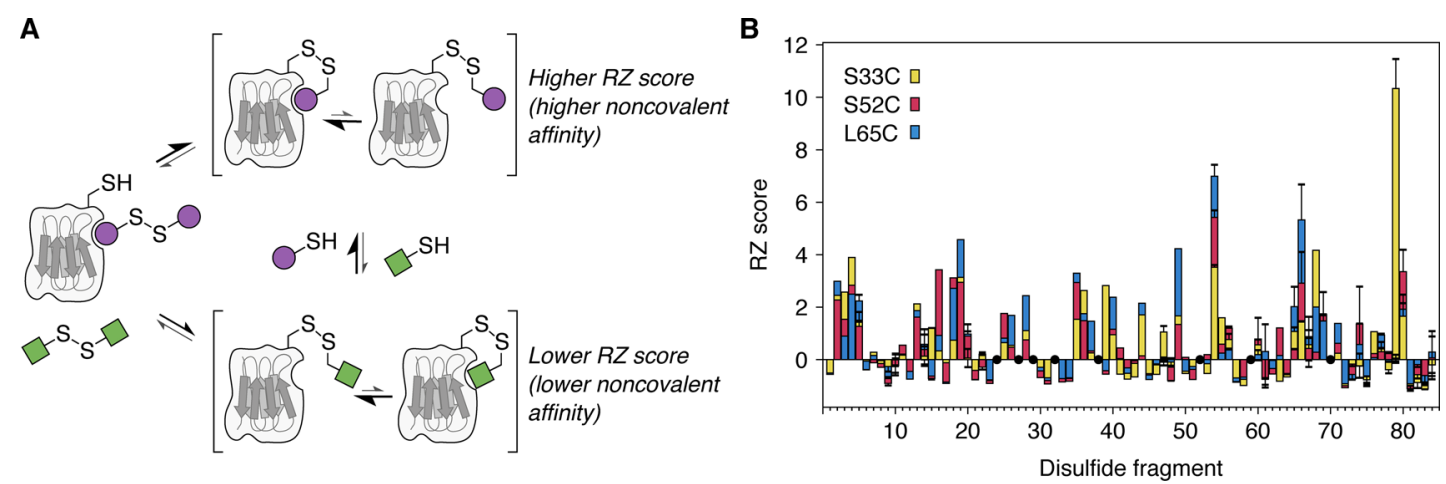

Figure 2. (A) Schematic representation of the disulfide tethering method used to compare noncovalent affinities of different fragments for specific target sites on $\Delta \mathrm{N} 6$. When using cocktails of fragments, the compound which forms the most favorable noncovalent interactions with the target protein while tethered by a disulfide bond will produce the most stable (i.e., highest populated) covalent protein-fragment adduct at equilibriumthis is reflected by a higher RZ score. (B) Data from a disulfide tethering screen against three $\Delta$ N6 cysteine variants (S33C, S52C, and L65C) normalized as RZ scores. For fragments which were present in more than one screening cocktail, data are shown as the mean \pm one standard deviation. Each cysteine variant was present at $5 \mu \mathrm{M}$ and was incubated for $24 \mathrm{~h}$ with $25 \mu \mathrm{M}$ of each disulfide-linked fragment (in cocktails of five fragments) and $500 \mu \mathrm{M} \beta \mathrm{ME}$, in $25 \mathrm{mM}$ sodium phosphate, $\mathrm{pH} 6.2,2 \% \mathrm{v} / \mathrm{v}$ DMSO. Black circles are shown for fragments which were synthesized but not included in the screening library due to poor purity.

Native monomeric $\beta_{2} \mathrm{~m}$ has a seven-stranded immunoglobulin fold and forms the noncovalently bound light chain of the major histocompatibility class I complex. ${ }^{29}$ Aberrant selfassembly of $\beta_{2} \mathrm{~m}$ molecules into amyloid fibrils ${ }^{30}$ is a hallmark of dialysis-related amyloidosis (DRA). ${ }^{31-33}$ The amyloidogenic variant of $\beta_{2} \mathrm{~m}$ which is the focus of this paper $-\Delta \mathrm{N} 6-\mathrm{is}$ formed from the wild-type protein by proteolysis of its $\mathrm{N}$ terminal six amino acids and makes up $\sim 20-30 \%$ of $\beta_{2} \mathrm{~m}$ molecules found in fibrils extracted from DRA patients. ${ }^{34,35}$ $\Delta \mathrm{N} 6$ is capable of rapid assembly into amyloid fibrils in vitro at near-neutral $\mathrm{pH}$, through the association of the dynamically structured monomers ${ }^{36}$ into dimers and hexamers that retain a nativelike fold $^{37}$ (Figure 1A). Subsequent conformational rearrangement of these oligomers into cross- $\beta$ structures leads to amyloid fibril formation and elongation. ${ }^{38}$

Recent structural models of $\Delta \mathrm{N} 6$ dimers and hexamers have shown that the $\mathrm{DE}$ and $\mathrm{BC}$ loops of the protein are involved in both oligomerization interfaces (Figure 1A). ${ }^{37}$ The same regions have also been identified at the interface of amyloidcompetent $\Delta \mathrm{N} 6-\beta_{2} \mathrm{~m}$ heterodimers, ${ }^{40} \quad \beta_{2} \mathrm{~m}-\beta_{2} \mathrm{~m}$ homo- dimers, ${ }^{41}$ and inhibitory heterodimers formed between $\Delta \mathrm{N} 6$ and a nonamyloidogenic $\beta_{2} \mathrm{~m}$ ortholog (murine $\beta_{2} \mathrm{~m}$ ). ${ }^{40}$ These examples implicate the $\mathrm{DE}$ and $\mathrm{BC}$ loops, and thereby also the associated $\beta$-strands, as mediators of oligomerization, and thus targeting these regions (e.g., by small molecules) was anticipated to yield tools for controlling and studying $\Delta \mathrm{N} 6$ self-assembly. The dynamic nature of $\Delta \mathrm{N} 6$ monomers $^{36}$ and oligomers, ${ }^{37}$ combined with the lack of an obvious ligand binding pocket, has thus far hindered the development of small molecule modulators of amyloid formation (although proteinbased modulators have been identified ${ }^{42}$ ). In light of this challenge, we focused our efforts on the development of covalent ligands to manipulate $\Delta \mathrm{N} 6$ self-assembly, based on the success of such compounds in targeting other challenging PPIs. ${ }^{43-45}$

\section{RESULTS AND DISCUSSION}

Identifying Covalent Ligands for $\Delta \mathrm{N} 6$ by Disulfide Tethering. Computational solvent mapping (using the FTMap server ${ }^{46}$ ) was performed against an NMR-derived 
conformational ensemble of $\Delta \mathrm{N} 6^{36}$ in order to predict which regions of the protein are likely to be hot spots for small molecule binding. The resulting data (Figure S1) highlighted two pockets adjacent to the $\mathrm{DE}$ and $\mathrm{BC}$ loops as promising targets for ligand development (site 1 , between the $\mathrm{C}$ and $\mathrm{D}$ strands; and site 2, beneath the DE loop; Figure 1B). To identify possible covalent ligands for these sites, a library of small molecules was screened using the "disulfide tethering" $\operatorname{method}^{26}$ (Figure 2A). First developed by Erlanson and coworkers as a site-directed screening strategy, ${ }^{47}$ this approach uses disulfide bonds to covalently trap and assess the interaction affinity of small molecules (typically fragments) which have bound noncovalently to the protein of interest. Libraries of disulfide-functionalized molecules are screened for their ability to form disulfide bonds with cysteine variants of the target protein, as small molecules which exhibit favorable noncovalent interactions near the free, solvent-exposed cysteine residue will undergo thiol-disulfide exchange more effectively due to their increased local concentration. The relative population of different covalent protein-ligand complexes at equilibrium can therefore be used as a proxy for the noncovalent affinity of a given fragment for a particular region of the target protein.

Three single cysteine variants of $\Delta \mathrm{N} 6$ (S33C, S52C, and L65C; Figure 1B) were expressed and purified (Figure S2) in order to monitor small molecule binding at sites 1 and 2 by using the disulfide tethering approach. A library of 84 symmetrical disulfides (designed with the aid of molecular docking, as described in the Supporting Information) was prepared through the use of solid-phase synthesis, and 76 of these fragments were sufficiently pure for screening purposes (Figure S3) and were screened against each $\Delta \mathrm{N} 6$ cysteine variant in cocktails of five, in the presence of excess reducing agent $(\beta$-mercaptoethanol, $\beta \mathrm{ME}$; Figure $S 4)$. The relative populations of the different protein-fragment adducts were assessed at $24 \mathrm{~h}$ by electrospray ionization mass spectrometry and normalized as robust Z (RZ) scores $^{48}$ (Figure 2B; Figures S5-S7), where higher RZ scores were anticipated to reflect more favorable protein-fragment interactions (Figure 2A). Comparison of the distribution of protein-fragment adducts observed for the three $\Delta \mathrm{N} 6$ cysteine variants to that of an unrelated, largely helical control protein, MCL-1, showed that there was poor correlation between the datasets for S52Cand L65C $-\Delta \mathrm{N} 6$ with that for MCL-1 (median $r=0.37$; Figure S6) and therefore that the identity of the protein affects which protein-fragment adducts dominate at equilibrium. The higher correlation between the datasets for S33C $-\Delta \mathrm{N} 6$ and MCL-1 reflects the similar chemical nature of their binding pockets (Figure S6). These observations suggest that the preference of $\Delta \mathrm{N} 6$ for particular fragments (as shown in Figure $2 \mathrm{~B}$ ) is a result of specific noncovalent interactions. RZ scores were therefore used to report on the relative noncovalent affinities of tethered fragments for a particular region on the surface of $\Delta \mathrm{N} 6$.

Covalent Functionalization and Ligand Binding Drive $\Delta$ N6 Tetramerization. To interrogate how covalent modification of the different regions of $\Delta \mathrm{N} 6$ affects aggregation, sedimentation velocity analytical ultracentrifugation (SV-AUC) was used to assess the oligomeric state of a series of individual protein-fragment adducts (Figure 3A; Figures S8-S10). Fragments with a range of RZ scores were selected for testing with each cysteine variant, so as to distinguish between changes in oligomeric state which are due
A

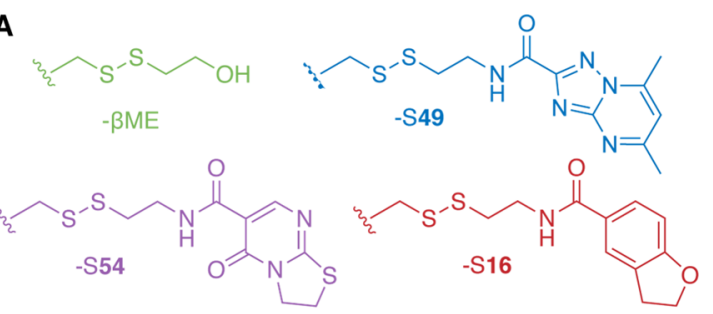

B

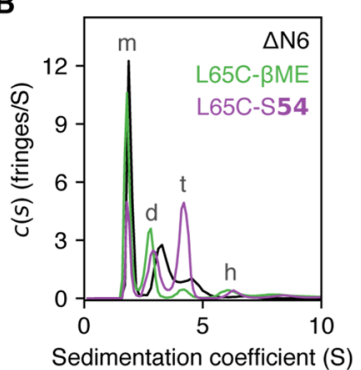

C

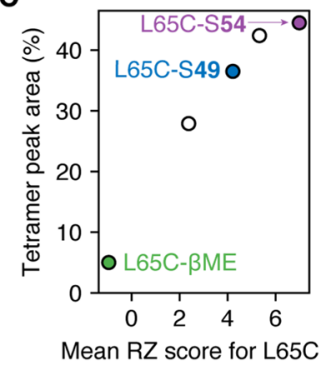

D

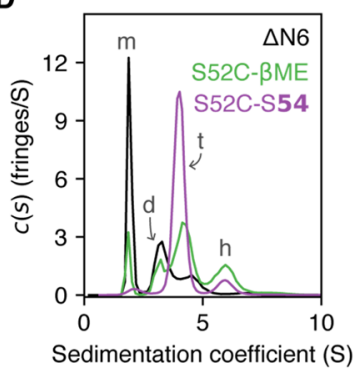

E

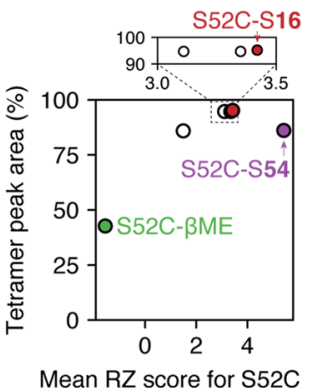

Figure 3. (A) Examples of fragments used to form the S52C- and L65C-fragment adducts studied by SV-AUC. (B-E) SV-AUC data collected for L65C-fragment adducts (B, C) or S52C-fragment adducts (D, E). Experiments were performed with $150 \mu \mathrm{M}$ protein in $25 \mathrm{mM}$ sodium phosphate at $\mathrm{pH} 6.2,25{ }^{\circ} \mathrm{C}$. Peaks in the $c(s)$ distributions were assigned to monomer $(\mathrm{m})$, dimer $(\mathrm{d})$, tetramer $(\mathrm{t})$, or hexamer $(\mathrm{h})$, based on previous studies ${ }^{37}$ and predicted sedimentation coefficients for these oligomers (calculated using the Svedberg equation ${ }^{49}$ ). Tetramer peak areas for a range of L65Cfragment adducts were found to correlate with the RZ score of the attached fragment $(\mathrm{C})$. The relationship between fragment RZ score and tetramer peak area for S52C-fragment adducts was less clear, and other properties of the fragments may play a role in modulating tetramer populations (E) (see Figure S14).

to covalent modification of the protein (i.e., changes observed for all samples of a given cysteine variant) versus changes which arise from specific noncovalent protein-ligand interactions (i.e., those observed only for covalently tethered fragments with high $\mathrm{RZ}$ scores).

In the absence of covalent modification, $\Delta \mathrm{N} 6$ is approximately $50 \%$ monomeric under the conditions employed ( 150 $\mu \mathrm{M}$ protein, $\mathrm{pH} 6.2,25{ }^{\circ} \mathrm{C}$ ), with dimers, tetramers, and hexamers representing the majority of faster sedimenting species (Figure S2), consistent with previous reports. ${ }^{37}$ Tethering of high RZ score fragments to all three $\Delta \mathrm{N} 6$ cysteine variants was found to increase the population of tetramers (representative data in Figure 3B,D; see also Figures S11-S13). Tethering with low RZ score fragments, however, produced a variety of results, which depended both on the cysteine variant and the ligand employed.

For L65C-fragment adducts, the area of the tetramer peak in the continuous sedimentation coefficient $(c(s))$ distributions showed a positive correlation with the $\mathrm{RZ}$ score of the tethered 
fragment (Figure 3C; Figures S13, S14): a covalently attached fragment with a low $\mathrm{RZ}$ score $(\beta \mathrm{ME})$ produced an oligomer distribution which was similar (albeit not identical) to that of $\Delta \mathrm{N} 6$ alone (tetramer peak areas of 5 and $18 \%$, respectively), while tethered fragments with high RZ scores produced significantly larger tetramer peaks (e.g., a $45 \%$ tetramer peak area was observed for the adduct between L65C and disulfide 54, named L65C-S54; Figure 3B,C). The only predicted ligandable pocket that is near residue 65 of $\Delta \mathrm{N} 6$ is target site 2 (Figure 1B), suggesting that the formation of tetramers by L65C-fragment adducts is driven by noncovalent binding to this pocket.

The nature of the relationship between tetramer population and fragment $\mathrm{RZ}$ score for the S52C- and S33C-fragment adducts was less clear. All S52C-fragment adducts produced tetramer peak areas of $\geq 43 \%$ (with most between 86 and 95\%), regardless of RZ score (Figure 3D,E; Figures S12, S14), implying that a different property of the fragments was driving the changes in oligomeric state at this site. Although a limited range of fragment sizes were used in screening, the observed tetramer populations for the different S52C-fragment adducts are consistent with fragment size (and thus the surface topography of protein-fragment adducts) being a contributing factor (Figure S14). The S33C-fragment adducts analyzed were generally polydisperse, with only two samples (of seven analyzed) producing $c(s)$ distributions which were readily interpretable (Figure S11): S33C- $\beta \mathrm{ME}$ and S33C-S79, the latter of which showed an increased tetramer peak area (43\%) over the former (16\%). These data are insufficient to ascertain which characteristic (characteristics) of the covalent fragments influences (influence) the tetramer population of S33Cfragment adducts, but they show that, as for L65C and S52C, the addition of specific covalent fragments to S33C can be used to modulate oligomer distributions.

Tetramer Stabilization Inhibits Amyloid Assembly. The ability of covalently tethered fragments to generate defined oligomer populations offered the opportunity to explore the effect of tetramer stabilization on $\Delta \mathrm{N} 6$ amyloid assembly. Protein-fragment adducts with a range of tetramer populations were added to preformed $\Delta \mathrm{N} 6$ amyloid fibrils, and the ability of these samples to elongate the fibril seeds was analyzed using the fluorescent, fibril-binding dye, thioflavin $\mathrm{T}$ (ThT). ${ }^{50,51}$ By using this strategy, fibril elongation by each sample will be templated by seeding to a common fibril product, irrespective of the covalent ligand, enabling direct comparison of the initial rates of fibril growth for different protein-fragment adducts. It should be noted that, under the conditions employed, spontaneous (i.e., unseeded) fibril formation does not occur on the time scale of the experiment.

For all three $\Delta \mathrm{N} 6$ cysteine variants, the observed initial elongation rates were lower for samples with higher tetramer populations (Figure 4; Figure S15A,B). The most dramatic change in fibril elongation was seen for S52C-S54 (86\% tetramer peak area in the $c(s)$ distribution), where the rate of elongation was reduced more than 30 -fold relative to $\Delta \mathrm{N} 6$ (Figure 4E,F). Global linear regression analysis across all samples showed that there is a negative correlation $(r=-0.78)$ between the observed initial fibril elongation rate and tetramer population, and extrapolation of the linear regression line to $100 \%$ tetramer corresponds precisely to an elongation rate of zero (Figure S15B). Together, these observations indicate that the tetramers formed by the S33C-, S52C-, and L65Cfragment adducts lie off-pathway to amyloid fibril formation.
A

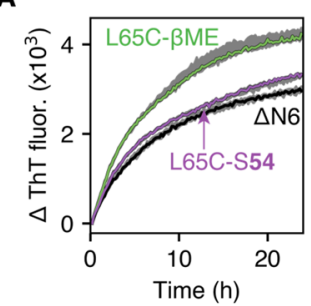

C

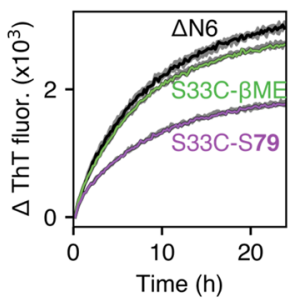

E

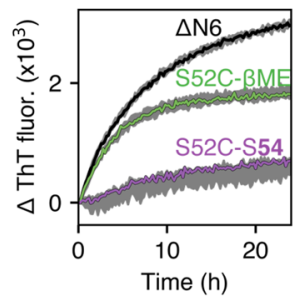

B

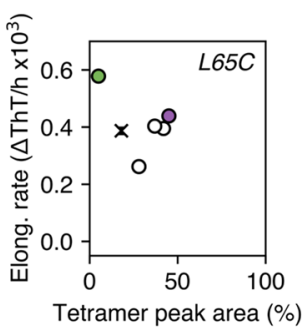

D

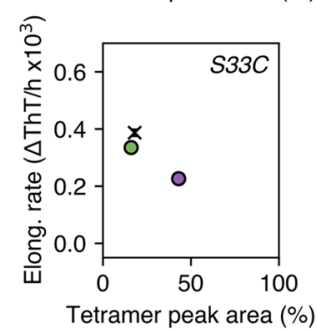

F

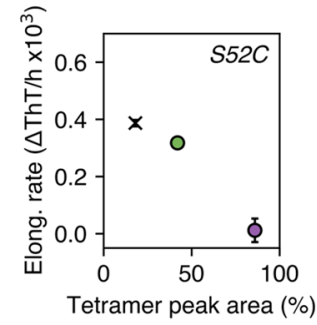

Figure 4. Change in ThT fluorescence over time for various proteinfragment adducts $(150 \mu \mathrm{M})$ in the presence of $\Delta \mathrm{N} 6$ fibril seeds (15 $\mu \mathrm{M}$ monomer equivalents) shows that the ability of samples to elongate fibrils depends on the tetramer population. ThT fluorescence curves in (A), (C), and (E) are shown as the median curve, with the highest and lowest values shaded in gray $(n=3)$. The relationship between the initial elongation rates calculated from these curves and the tetramer peak areas from the corresponding $c(s)$ distributions are shown in (B), (D), and (F). Error bars (standard deviation) are shown for all data points (mean values) in (B), (D), and (F)-those error bars that are not visible are smaller than the displayed data point. Additional ThT fluorescence curves associated with (B) which were not shown in (A) (i.e., the white circles in (B)) are shown in Figure S15A. All experiments were performed under quiescent conditions in $25 \mathrm{mM}$ sodium phosphate at $\mathrm{pH} 6.2,25{ }^{\circ} \mathrm{C}$. Elongation rates for unliganded $\Delta \mathrm{N} 6$ are shown by black crosses in (B), (D), and (F).

Prediction of elongation rates using kinetic schemes in which tetramers lie on- or off-pathway to fibrils also supports this conclusion (Figure S16). The fibril elongation data thus highlight tetramer stabilization as a strategy to inhibit $\Delta \mathrm{N} 6$ amyloid formation. In addition, they support a model in which covalent functionalization and covalent reinforcement of ligand binding around the $\mathrm{DE}$ and $\mathrm{BC}$ loops can be used to slow the progression of seeded amyloid formation by modulating the stability and population distribution of oligomers.

Structural Characterization of Stabilized Tetramers. To understand how the tetramers generated by the covalent modification of $\Delta \mathrm{N} 6$ are structurally related to the previously characterized $\Delta \mathrm{N} 6$ dimers and hexamers, ${ }^{37}$ as well as how and why covalent modification around the $\mathrm{DE}$ and $\mathrm{BC}$ loops leads to tetramerization, X-ray crystallography and solution-state NMR structural studies were performed.

S52C-S54 was found to crystallize as a ring-shaped tetramer with a solvent-accessible central cavity, formed from two asymmetric units each containing two $\Delta \mathrm{N} 6$ molecules in an antiparallel orientation (Figure $5 \mathrm{~A}-\mathrm{C}$; Table S1). As seen for 
A
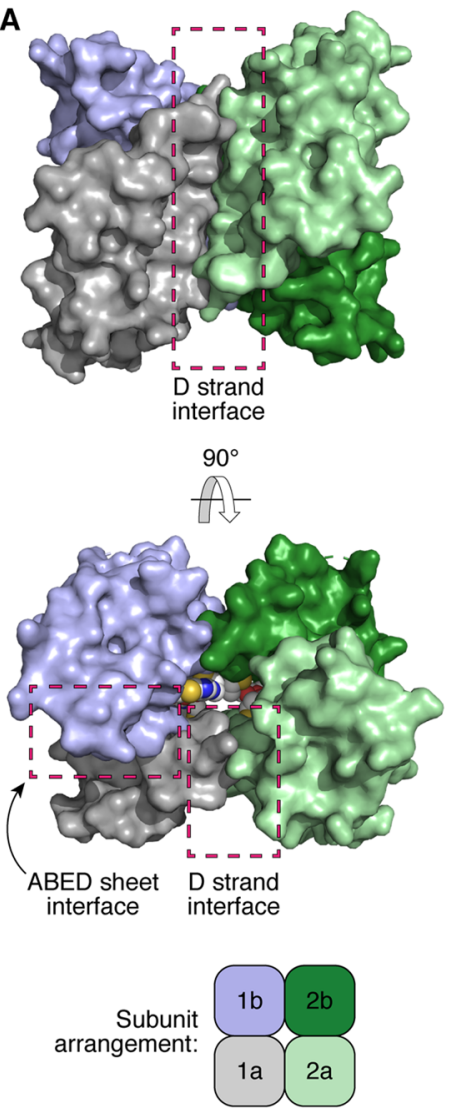
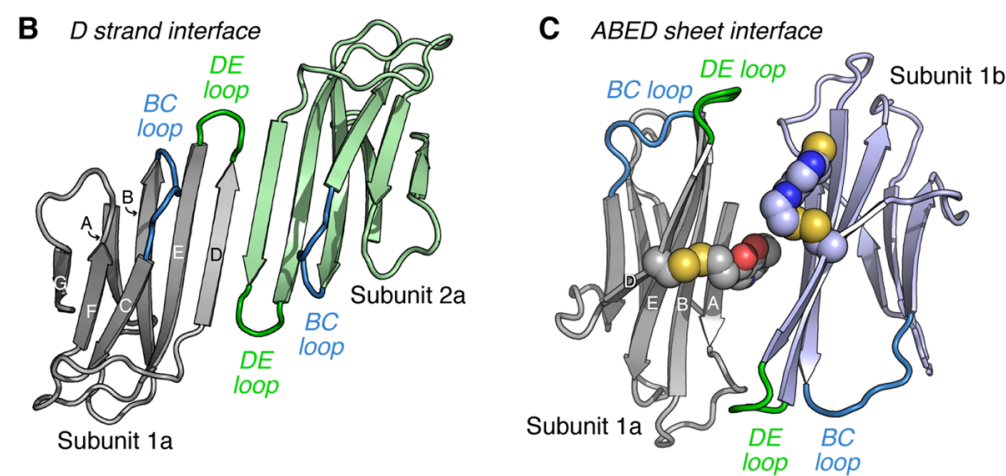

D Crystal structure: tetramer RMSD relative to monomer
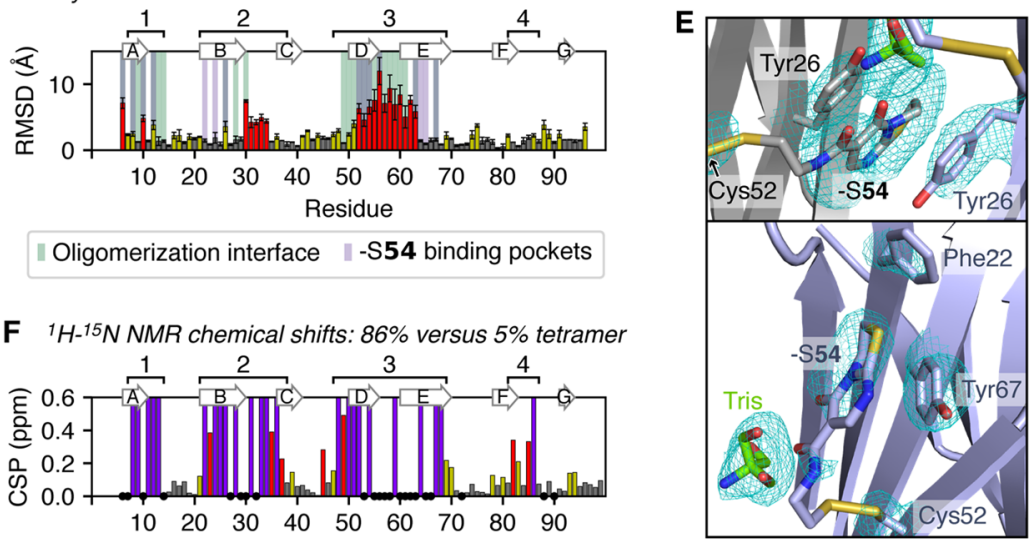

Figure 5. (A-C) Crystal structure of the S52C-S54 tetramer (diffracted to $2.4 \AA$; PDB 7AFV), formed from two asymmetric units: subunits 1a/ $1 \mathrm{~b}$ (gray/pale blue) and subunits $2 \mathrm{a} / 2 \mathrm{~b}$ (pale green/dark green). Protein subunits interact via two interfaces: the $\mathrm{D}$ strand interface (B) and the ABED sheet interface (C). Four copies of the covalent -S54 fragment (shown as spheres in A and C) are present in this complex and lie within the ABED sheet interface, in a central solvent-accessible cavity (C). (D) Per-residue, pairwise RMSD values for the S52C-S54 tetramer crystal structure (subunit 1a/2a) compared with the monomeric $\Delta$ N6 NMR ensemble (30 structures; PDB $2 X K U^{36}$ ), reported for all non-hydrogen atoms as the mean RMSD ( \pm standard deviation). Residues which are $\leq 6 \AA$ from another protein subunit or a $-\mathrm{S} 54$ fragment within the S52CS54 tetramer structure are additionally highlighted by green or purple bars, respectively. The locations of the $\beta$-strands in the S52C-S54 tetramer crystal structure are shown above the plot. (E) Each -S54 fragment can bind in one of two binding sites around the site 2 pocket: by $\pi$ stacking between two Tyr26 residues within the ABED sheet interface (top) or by $\pi$ stacking against Tyr67 (bottom). The 2 Fo-Fc electron density map (contoured at $1.1 \sigma$ ) is shown in cyan for the displayed amino acid side chains and organic molecules. (F) Combined ${ }^{1} \mathrm{H}-{ }^{15} \mathrm{~N}$ chemical shift differences between S52C-S54 and L65C- $\beta$ ME HMQC NMR spectra-these samples had tetramer peak areas of 86 and $5 \%$, respectively, in their $c(s)$ distributions. Residues which were not visible (or could not be confidently assigned based on comparison with previous $\Delta \mathrm{N} 6$ assignments ${ }^{36}$ ) for either sample are shown as black circles. Residues which were visible for L65C- $\beta \mathrm{ME}$ but were broadened beyond detection for S52C-S54 are shown by purple bars. Resonances which were visible in both spectra are colored according to the magnitude of the chemical shift perturbation (CSP) relative to the standard deviation of the dataset $(\sigma)$ : CSP $\geq 2 \sigma$, red; $\sigma \leq \mathrm{CSP}<2 \sigma$, yellow; CSP $<\sigma$, gray. Four main regions (labeled $1-4$ ) show either significant changes in the position of ${ }^{1} \mathrm{H}-{ }^{15} \mathrm{~N}$ resonances or complete loss of these resonances in samples with higher tetramer populations (see also Figure S21).

the on-pathway $\Delta \mathrm{N} 6$ dimer and hexamer, ${ }^{37}$ the protein subunits in the crystallized tetramer are highly nativelike, but notably with perturbations to the DE and BC loops as well as a shift of the $\mathrm{D}$ strand from a $\beta$-bulge to a straight $\beta$-strand (Figure 5D; Figure S17A). These structural changes appear to be linked to each other and to tetramerization: straightening of the D strand allows for protein-protein interactions to occur via $\beta$-sheet augmentation, forming one of the two interaction interfaces in the tetramer (Figure $5 \mathrm{~B}$ ), and additionally results in a rearrangement of phenylalanine residues at the top of the D, E, and B strands (Phe56, Phe62, and Phe30, respectively) which is accommodated by rearrangement of the $\mathrm{BC}$ loop (Figure S17B). This movement of residues around the BC and DE loops allows several key protein-protein contacts to be made within the second interaction interface, which occurs through a face-to-face, antiparallel interaction of the ABED $\beta$ sheets (Figure 5C; Figure S17C).
Clear electron density indicated the presence of four covalently bound -S54 fragments within the central cavity of the tetramer (Figure 5A; bottom structure) which make intrasubunit and/or intersubunit contacts with the site 2 pocket of surrounding protein subunits (Figure 5E; Figure $\mathrm{S} 17 \mathrm{C}$ ). The protein-ligand interactions with the strongest electron density, and which are therefore the interactions which presumably contribute most to the stabilization of the tetramer, involve $\pi$ stacking between two Tyr26 residues within the ABED sheet interface and the bicyclic ring system of a fragment 54 molecule (gray ligand in Figure 5E) - this arrangement is seen for two of the four fragments in a tetramer. These protein-ligand interactions may additionally stabilize the straight conformation of the D strand: residue 52 lies too far from Tyr26 in the monomeric $\Delta \mathrm{N} 6$ structure for fragment 54 to interact with Tyr26, and it thus appears that this protein-ligand interaction can only form when the $\mathrm{D}$ strand is 
straight (Figure S17D). Therefore, while no direct proteinligand contacts occur with either the $\mathrm{DE}$ or $\mathrm{BC}$ loops, contacts with the associated $\beta$-strands appear to have driven conformational changes in these regions, and together the observed structural changes have altered the $\Delta \mathrm{N} 6$ self-assembly landscape in favor of the tetramer. The electron density associated with the remaining two fragments in the tetramer is not as well-defined as for those intercalated between Tyr26 residues, but it suggests a binding mode whereby the fragments can form intrasubunit $\pi-\pi$ interactions with Tyr67 residues (Figure 5E, pale blue ligand).

${ }^{1} \mathrm{H}-{ }^{15} \mathrm{~N}$ heteronuclear multiple quantum coherence (HMQC) NMR spectra and ${ }^{15} \mathrm{~N}$-relaxation measurements acquired for various S52C - and L65C-fragment adducts were consistent with the tetramer observed within the S52C-S54 crystal lattice, implying that this crystal structure reflects the nature of these off-pathway $\Delta \mathrm{N} 6$ tetramers in solution (Figures S18-S21). Comparison of the chemical shifts and intensities of ${ }^{1} \mathrm{H}-{ }^{15} \mathrm{~N}$ backbone amide resonances between samples with higher tetramer populations (e.g., S52C-S54 and L65C-S54) and those with lower tetramer populations (e.g., $\Delta \mathrm{N} 6$, L65C $-\beta \mathrm{ME}$ ) showed differences across four regions of primary sequence (labeled $1-4$ in Figure $5 \mathrm{~F}$ and Figure S21). Regions 1-3 contain residues that either make up the tetramer interaction interfaces and/or have shifted significantly ( $\geq 4 \AA$ root-mean-square deviation, RMSD) in the crystal structure relative to monomeric $\Delta \mathrm{N} 6$ (Figure 5D). While region 4 does not undergo any structural changes itself in the crystal structure, it is adjacent to the BC loop, and hence residues in region 4 will experience a change in chemical environment upon tetramerization (Figure 5D).

In addition to the NMR data supporting the relevance of the S52C-S54 crystal structure to oligomerization in solution, the NMR data also indicate that the tetramers formed by the S52C- and L65C-fragment adducts are structurally similar. The ability of S52C - and L65C-fragment adducts to adopt similar tetrameric species can be rationalized in the context of the crystal structure. D strand straightening results in residues 52 and 65 now lying adjacent to one another (Figure S17A, inset), so we anticipate that fragments tethered to the L65C variant of $\Delta \mathrm{N} 6$ can access the same binding pockets which -S54 is observed to occupy in the S52C-S54 crystal structure.

Structural Similarities of Off-Pathway $\Delta$ N6 Tetramers with Full-Length $\boldsymbol{\beta}_{2} \mathrm{~m}$ Oligomers. While similar regions of $\Delta \mathrm{N} 6$ are involved in the formation of the off-pathway tetramer and the previously identified on-pathway dimers/hexamers (which were characterized under conditions similar to those employed here), ${ }^{37}$ the PPIs themselves are significantly different and mutually exclusive (Figure S22A). This observation rationalizes the off-pathway behavior of the tetramer, as it would need to completely dissociate to form the on-pathway hexamer. However, although the tetramer is different from previously identified $\Delta \mathrm{N} 6$ oligomers, ${ }^{37,42,52}$ its interfaces resemble those observed in oligomers of the fulllength $\beta_{2} \mathrm{~m}$ protein. ${ }^{53-56}$ The most striking similarities are those with a crystallographic tetramer formed by the P32A variant (PDB 2F8O; ${ }^{53}$ Figure S22B,C). P32A $\beta_{2} \mathrm{~m}$ is largely monomeric in solution ${ }^{53}$ (in the absence of divalent copper ${ }^{57}$ ), but at the high concentrations within the crystal lattice the protein molecules can interact via the same $\mathrm{D}$ strand and ABED interfaces shown in Figure 5 (Figure S22B). Although the solution relevance of the crystallographic P32A tetramer was not shown, the NMR data obtained for S52C-S54 confirm that this arrangement of protomers is possible in solution and stable in the presence of suitable ligands.

While the crystallographic P32A $\beta_{2} \mathrm{~m}$ tetramer possesses the same straight D strand as the S52C-S54 $\Delta \mathrm{N} 6$ tetramer, other $\beta_{2} \mathrm{~m}$ oligomers for which high-resolution structural information is available lack straight $\mathrm{D}$ strands and instead involve $\mathrm{DE}$ and BC loop-mediated PPIs. ${ }^{54-56}$ Since these oligomers which lack straight D strands have been shown (or proposed) to be onpathway species, we hypothesize that formation of an eightstranded ABED-DEBA $\beta$-sheet is an off-pathway PPI which can be driven by ligand binding across the ABED sheet (as seen for $\Delta \mathrm{N} 6 \mathrm{~S} 52 \mathrm{C}-\mathrm{S54}$ ) or modulation of the BC loop (as for $\beta_{2} \mathrm{~m} \mathrm{P32A}$ ).

\section{CONCLUSIONS}

Covalent small molecules are becoming increasingly attractive tools to modulate specific protein-protein interactions, ${ }^{44,45,58-60}$ to interrogate the role of different proteins in biological processes, ${ }^{45,58,61-63}$ and to facilitate structural studies of challenging targets. ${ }^{43,64}$ The results presented here expand this covalent chemical tool approach, highlighting its power to facilitate analysis of the structure and the role of specific oligomers in self-assembly pathways. We have demonstrated that covalently reinforced protein-ligand interactions ${ }^{65,66}$ can be used to manipulate heterogeneous and dynamic PPIs, exemplified by those formed in the initial stages of amyloid formation, which are notoriously difficult to target selectively when purely noncovalent approaches are used. ${ }^{67}$ Specifically, covalent ligands identified by disulfide tethering allowed a transient off-pathway tetramer (as shown by kinetic data and models) formed by the amyloidogenic $\Delta \mathrm{N} 6$ variant of $\beta_{2} \mathrm{~m}$ to be trapped and characterized in atomic detail for the first time. These results highlight the power of the chemical modification of proteins as a general strategy to manipulate complex self-assembling systems and to drive the formation of defined oligomers for detailed study.

\section{EXPERIMENTAL SECTION}

Safety. No unexpected, new, and/or significant hazards or risks were associated with this research.

Disulfide Tethering Screening. Screening cocktails were prepared by combining five disulfide-linked fragments $(1.25 \mathrm{mM}$ each; all present as symmetrical disulfides) in the presence of $\beta \mathrm{ME}$ $(25 \mathrm{mM})$ in DMSO. These initial cocktail mixtures were incubated at ambient temperature $\left(\sim 18{ }^{\circ} \mathrm{C}\right)$ for $12 \mathrm{~h}$ to allow the formation of mixed disulfides with $\beta \mathrm{ME}$ (which generally had improved aqueous solubility over the symmetrical disulfides).

Screening cocktails were diluted further into each $\Delta \mathrm{N} 6$ cysteine variant ( $5 \mu \mathrm{M}$ protein, with $25 \mu \mathrm{M}$ each disulfide, $500 \mu \mathrm{M} \beta \mathrm{ME}, 2 \%$ $\mathrm{v} / \mathrm{v}$ DMSO) in $25 \mathrm{mM}$ sodium phosphate at either $\mathrm{pH} 6.2$ (main text data) or $\mathrm{pH} 8.0$ (Supporting Information), and the resulting screening mixtures were incubated at ambient temperature. The distribution of covalent protein-fragment adducts over time was analyzed by a Bruker maXis Impact QTOF mass spectrometer, with an electrospray ionization source. Samples ( $1 \mu \mathrm{L}$ injections) were desalted prior to mass spectrometry by an in-line Dionex UltiMate 3000 liquid chromatography system (Thermo Scientific), equipped with an Aeris Widepore C4 column (Phenomenex), running a gradient between water and acetonitrile, both supplemented with $0.1 \%$ formic acid.

MCL-1 (residues 172-327; purified as described previously ${ }^{68}$ ) was screened using the same procedure, but in $25 \mathrm{mM}$ sodium phosphate, pH 7.4.

Mass spectra were deconvoluted with the use of a maximum entropy algorithm (DataAnalysis, Bruker). For each protein-fragment adduct in each cocktail, the intensity of the deconvoluted peak at $24 \mathrm{~h}$ 
was measured relative to the protein $-\beta \mathrm{ME}$ adduct peak. These relative intensities were then converted to $\mathrm{RZ}$ scores. ${ }^{48}$ The $\mathrm{RZ}$ score for a given fragment can be described by eq 1 :

$$
\mathrm{RZ}=\frac{x_{i}-\operatorname{median}\left(x_{\text {all }}\right)}{\operatorname{MAD}\left(x_{\text {all }}\right)}
$$

where $x_{i}$ is the relative intensity of the protein-fragment adduct peak for fragment $i$ and $x_{\text {all }}$ is a list of relative peak intensities for all protein-fragment adducts in that dataset (i.e., for a given cysteine variant at a given $\mathrm{pH}$ ). In all cases, peak intensities were measured relative to the $\beta \mathrm{ME}$ adduct. The medium absolute deviation $(\mathrm{MAD})^{69}$ is defined as

$$
\operatorname{MAD}\left(x_{\text {all }}\right)=1.4826 \operatorname{median}\left(\left|x_{i}-\operatorname{median}\left(x_{\text {all }}\right)\right|\right)
$$

RZ scores for the disulfide analogue of $\beta \mathrm{ME}$ could not be determined by this method, due to the presence of $\beta \mathrm{ME}$ as a reducing agent in all screening mixtures. Instead, its RZ score was estimated through competition experiments, as shown in Figure S7.

Sedimentation Velocity Analytical Ultracentrifugation. Experiments were carried out at $48000 \mathrm{rpm}, 25^{\circ} \mathrm{C}$, with an An50$\mathrm{Ti}$ rotor in a Beckman Coulter Optima XL-I ultracentrifuge. Samples and reference buffer $(400 \mu \mathrm{L})$ were loaded into $12 \mathrm{~mm}$ aluminum centerpieces, with sapphire windows. Samples were thermally equilibrated for $2-3 \mathrm{~h}$ at $0 \mathrm{rpm}$ and were subsequently analyzed using the interference detection system at a protein concentration of $150 \mu \mathrm{M}$ in $25 \mathrm{mM}$ sodium phosphate, $\mathrm{pH}$ 6.2. All samples had been exhaustively dialyzed in this buffer prior to loading, and the dialysate was used as the reference buffer.

Data were analyzed in SEDFIT (version 12.44) ${ }^{70}$ with a continuous $c(s)$ distribution model and with a maximum entropy regularization confidence interval of 0.95 . Values for the partial specific volume $(\bar{\nu})$ of $\Delta \mathrm{N} 6$, buffer viscosity $(\eta)$, and buffer density $(\rho)$ were all calculated with SEDNTERP ${ }^{71}(\bar{\nu}=0.72832 \mathrm{~mL} / \mathrm{g} ; \eta=$ $0.00898 \mathrm{P}$ and $\rho=0.99954 \mathrm{~g} / \mathrm{mL}$ for $25 \mathrm{mM}$ sodium phosphate, $\mathrm{pH}$ 6.2). The final fitting was performed with the Levenberg-Marquardt algorithm, although initial fitting was performed with both the Simplex and Levenberg-Marquardt algorithms. For $c(s)$ distributions with significant peak broadening or overlap, further processing was subsequently performed to permit baseline resolution of these peaks: multiple Gaussian functions were fit to the initial $c(s)$ distribution (using the curve fit function from SciPy.optimize), and then the positions of these best fit Gaussians were used in SEDFIT as Bayesian prior expectations ${ }^{72}$ (modeled again as Gaussians, located at the best fit positions identified by curve fit, with widths set to 0.2 and amplitudes set to 0.1). Refitting the data with the LevenbergMarquardt algorithm led to improved or equally good root-meansquare deviations (compared to the original $c(s)$ distribution) for all datasets to which this processing method had been applied, confirming the validity of this approach.

Peaks in the $c(s)$ distributions were assigned to specific oligomers based on comparison to published $\Delta \mathrm{N} 6$ SV-AUC data ${ }^{37}$ and predicted sedimentation coefficients for these oligomers. Predicted sedimentation coefficients were calculated with the Svedberg equation ${ }^{49}$ at a range of possible frictional ratios, so as to estimate the range of possible sedimentation coefficients which could describe a particle of a given molecular weight.

Thioflavin T Aggregation Assays. Protein-fragment adducts $(150 \mu \mathrm{M})$ were incubated in $25 \mathrm{mM}$ sodium phosphate, $\mathrm{pH}$ 6.2, with $10 \mu \mathrm{M} \mathrm{ThT}$, in the presence or absence of $15 \mu \mathrm{M}$ (monomer equivalent) fibril seeds prepared from $\Delta \mathrm{N} 6$, in 96-well untreated halfarea plates (Corning; $100 \mu \mathrm{L}$ sample per well). In the same plate, 15 $\mu \mathrm{M}$ (monomer equivalent) fibril seeds were incubated alone in 25 $\mathrm{mM}$ sodium phosphate, $\mathrm{pH}$ 6.2. Details concerning the preparation of fibril seeds can be found in the Supporting Information.

Fibril elongation was allowed to occur quiescently, with brief agitation $(10 \mathrm{~s}$ at $600 \mathrm{rpm})$ only occurring prior to each reading (every $12 \mathrm{~min}$ ). Experiments were performed for $24 \mathrm{~h}$ at $25{ }^{\circ} \mathrm{C}$ in a FLUOstar OPTIMA plate reader (BMG Labtech), exciting ThT at $444 \mathrm{~nm}$ and measuring its fluorescence emission intensity at $480 \mathrm{~nm}$.
Data were processed by subtracting two datasets from each seeded dataset to remove changes in ThT fluorescence which had occurred independently of fibril elongation: (a) data obtained from the same protein-fragment adduct in the absence of fibril seeds; (b) data obtained for fibril seeds alone in buffer. The absence of fibrillar aggregates in the unseeded samples after $24 \mathrm{~h}$ was confirmed by negative-stain electron microscopy (see Supporting Information). Initial elongation rates from the processed seeded datasets were measured by fitting a straight line to the first $3 \mathrm{~h}$ of data and determining the gradient.

Protein Crystallography and Data Processing. A stock solution of S52C-S54 was prepared by incubation of S52C (1.5 $\mathrm{mM})$ and the symmetrical disulfide of fragment 54 (Di-S54; $1.5 \mathrm{mM})$ in $25 \mathrm{mM}$ sodium phosphate, $\mathrm{pH} 8.0,725 \mu \mathrm{M} \beta \mathrm{ME}, 20 \% \mathrm{v} / \mathrm{v}$ DMSO, for $40 \mathrm{~h}$ at room temperature, before exhaustive dialysis against 25 $\mathrm{mM}$ sodium phosphate, $\mathrm{pH} 6.2$, at $4{ }^{\circ} \mathrm{C}$, using dialysis tubes with a 3.5 $\mathrm{kDa}$ molecular weight cutoff (Generon). The concentration of the dialyzed sample was determined through a bicinchoninic acid (BCA) assay. ${ }^{73}$ Crystals were grown by mixing $0.2 \mu \mathrm{L}$ of the proteinfragment complex $(1.1 \mathrm{mM})$ and $0.1 \mu \mathrm{L}$ of the crystallization solution in hanging drop plates at $293 \mathrm{~K}$. The crystallization solution $(39 \mathrm{mM}$ bicine, $61 \mathrm{mM}$ Tris, $\mathrm{pH} 8.5,7.8 \% \mathrm{w} / \mathrm{v}$ PEG 3350, 7.8\% w/v PEG $1000,7.8 \% \mathrm{v} / \mathrm{v} 2$-methyl-2,4-pentanediol, and $6.7 \mathrm{mM}$ each of 1,6hexanediol, 1-butanol, 1,2-propanediol, 2-propanol, 1,4-butanediol, and 1,3-propanediol) was prepared from Morpheus Buffer System 3 at pH 8.5, Morpheus Precipitant Mix 4, and Morpheus Alcohols Mix (all from Molecular Dimensions). After 2 weeks, crystals were fished and flash-frozen in liquid nitrogen. The diffraction data were collected at $0.9795 \AA$, with $0.025 \mathrm{~s}$ exposition and $0.15^{\circ}$ oscillation, for a total of 2400 images on beamline I24 at Diamond Light Source (U.K.). The data were processed using the xia $2^{74}$ bundle, with DIALS ${ }^{75}$ for integration and using Pointless/Aimless ${ }^{76,77}$ for scaling and merging. The data were processed using $\mathrm{CC} 1 / 2$ and completeness as cutoff criteria. $^{78}$ The structure of S52C-S54 was solved by molecular replacement, using full-length $\beta_{2} \mathrm{~m}\left(\mathrm{PDB} 5 \mathrm{CS} 7^{79}\right.$ ) with the first six amino acids removed as the search model in PHASER. ${ }^{80}$ COOT $^{81}$ and REFMAC5 ${ }^{82}$ were used for refinement. Parameterization of Cys-S54 (as a non-natural amino acid) was carried out in XPLOR$\mathrm{NIH},{ }^{83}$ followed by refinement of its structure using the fixupCovalentGeometry function while satisfying the electron density. The quality of the final structure was assessed with MolProbity. ${ }^{84}$ Data collection and refinement statistics are shown in Table S1. Figures were prepared using PyMOL (version 2.4, Schrödinger).

Protein NMR. All spectra were acquired by using a $750 \mathrm{MHz}$ Bruker Avance III HD spectrometer equipped with a TCI cryoprobe, at a protein concentration of $150 \mu \mathrm{M}$ in $25 \mathrm{mM}$ sodium phosphate, $\mathrm{pH} 6.2$, at $25{ }^{\circ} \mathrm{C} .{ }^{1} \mathrm{H}-{ }^{15} \mathrm{~N}$ SOFAST HMQC spectra were processed with the use of NMRPipe, ${ }^{85}$ and calculation of peak intensities was performed in CcpNmr Analysis (version 2.4) ${ }^{86}{ }^{1} \mathrm{H}-{ }^{15} \mathrm{~N}$ peaks were assigned to specific backbone resonances for each protein-fragment adduct (L65C $-\beta \mathrm{ME}, \mathrm{L} 65 \mathrm{C}-\mathrm{S} 54, \mathrm{~S} 52 \mathrm{C}-\beta \mathrm{ME}$, and S52C-S54) by comparison to existing $\Delta \mathrm{N} 6$ assignments, ${ }^{36}$ only considering peaks with intensities at least 3 -fold greater than the spectral noise. Backbone chemical shift perturbations (CSPs) between samples were calculated with eq 3 :

$$
\mathrm{CSP}=\sqrt{25 \Delta \delta_{\mathrm{HN}}^{2}+\Delta \delta_{\mathrm{N}}^{2}}
$$

where $\Delta \delta_{\mathrm{HN}}$ and $\Delta \delta_{\mathrm{N}}$ represent the difference in peak position in the direct and indirect dimensions, respectively.

L65C $-\beta \mathrm{ME}$ and L65C-S54 $\mathrm{T}_{2}$ experiments were performed by acquiring a series of sensitivity-enhanced ${ }^{1} \mathrm{H}-{ }^{15} \mathrm{~N}$ heteronuclear single quantum coherence (HSQC) spectra in an interleaved fashion at a range of delay times $(0.017-0.136 \mathrm{~ms}$ for L65C $-\beta \mathrm{ME}, 0.017-0.119$ $\mathrm{ms}$ for L65C-S54). Peak intensities (I) were extracted from each spectrum with the series.tab NMRPipe module, and per-residue ${ }^{15} \mathrm{~N}$ relaxation rates $\left(R_{2}\right)$ were calculated by fitting the peak intensity at different delay times $(t)$ to a two-parameter exponential function (eq 4). 


$$
I=-a \mathrm{e}^{-R_{2} t}
$$

For $\mathrm{S} 52 \mathrm{C}-\beta \mathrm{ME}$ and $\mathrm{S} 52 \mathrm{C}-\mathrm{S} 54$, sensitivity limitations did not permit the determination of ${ }^{15} \mathrm{~N} R_{2}$ rates on a per-residue basis. Instead, the first increment of the standard $T_{2}$ experiment at each delay time $(0.017-0.102 \mathrm{~ms}$ for S52C- $\beta \mathrm{ME}, 0.017-0.085 \mathrm{~ms}$ S52C-S54) was used to determine the $R_{2}$ rate of the whole amide region (7.6-9.2 ppm). Mean ${ }^{15} \mathrm{~N} R_{2}$ rates for the whole amide region were calculated in the same way for $\Delta \mathrm{N} 6(0.017-0.085 \mathrm{~ms})$ and the two L65C adducts (L65C- $\beta \mathrm{ME}$ and L65C-S54, using the same datasets acquired for determining per-residue ${ }^{15} \mathrm{~N}_{2}$ rates).

\section{ASSOCIATED CONTENT}

\section{SI Supporting Information}

The Supporting Information is available free of charge at https://pubs.acs.org/doi/10.1021/jacs.0c10629.

Supplementary materials and methods (including protein expression and purification, computational solvent mapping, design and synthesis of the disulfide fragment library, preparation of individual proteinfragment adducts, preparation of $\Delta \mathrm{N} 6$ fibril seeds for thioflavin $\mathrm{T}$ aggregation assays, and negative-stain transmission electron microscopy), and characterization of synthesized compounds (PDF)

\section{Accession Codes}

Coordinates of the $\Delta \mathrm{N} 6 \mathrm{~S} 52 \mathrm{C}-\mathrm{S} 54$ tetramer crystal structure have been deposited in the Protein Data Bank with the PDB code $7 \mathrm{AFV}$.

\section{AUTHOR INFORMATION}

\section{Corresponding Authors}

Sheena E. Radford - Astbury Centre for Structural Molecular Biology and School of Molecular and Cellular Biology, University of Leeds, Leeds LS2 9JT, United Kingdom; ○ orcid.org/0000-0002-3079-8039; Email: S.E.Radford@ leeds.ac.uk

Andrew J. Wilson - Astbury Centre for Structural Molecular Biology and School of Chemistry, University of Leeds, Leeds LS2 9JT, United Kingdom; 이이.org/0000-0001-98526366; Email: A.J.Wilson@leeds.ac.uk

\section{Authors}

Emma E. Cawood - Astbury Centre for Structural Molecular Biology, School of Chemistry, and School of Molecular and Cellular Biology, University of Leeds, Leeds LS2 9JT, United Kingdom; (1) orcid.org/0000-0002-2707-8022

Nicolas Guthertz - Astbury Centre for Structural Molecular Biology and School of Molecular and Cellular Biology, University of Leeds, Leeds LS2 9JT, United Kingdom

Jessica S. Ebo - Astbury Centre for Structural Molecular Biology and School of Molecular and Cellular Biology, University of Leeds, Leeds LS2 9JT, United Kingdom; (1) orcid.org/0000-0002-5684-4355

Theodoros K. Karamanos - Astbury Centre for Structural Molecular Biology and School of Molecular and Cellular Biology, University of Leeds, Leeds LS2 9JT, United Kingdom; Laboratory of Chemical Physics, National Institute of Diabetes and Digestive and Kidney Diseases, National Institutes of Health, Bethesda, Maryland 20892, United States; orcid.org/0000-0003-2297-540X

Complete contact information is available at: https://pubs.acs.org/10.1021/jacs.0c10629

\section{Author Contributions}

E.E.C., S.E.R, and A.J.W. conceived and designed the research program; E.E.C. designed studies and performed the research with support from N.G. (crystallography), J.S.E. (AUC), and T.K.K. (NMR). The manuscript was written by E.E.C., S.E.R., and A.J.W. with contributions from all authors. E.E.C. prepared all figures.

\section{Funding}

This work was supported by The Wellcome Trust (109154/Z/ 15/A, 204963, 109984, 097827/Z/11/A, WT094232MA, $108466 / \mathrm{Z} / 15 / \mathrm{Z}$, and $094232 / \mathrm{Z} / 10 / \mathrm{Z})$, EPSRC (EP/ N035267/1, EP/KO39292/1, EP/N013573/1), BBSRC (BB/M011151/1), and ERC (322408). A.J.W. holds a Royal Society Leverhulme Trust Senior Fellowship (SRF/R1/ 191087).

\section{Notes}

The authors declare no competing financial interest.

\section{ACKNOWLEDGMENTS}

The authors wish to thank Rodolfo Ghirlando for advice on SV-AUC procedures, data analysis, and interpretation, Pallavi Ramsahye for purification of the MCL-1 protein, Honghao Zhang and Zsófia Hegedüs for their work performing the MCL-1 tethering experiments, Arnout Kalvedra for assistance with NMR experiments, and Rodrigo Gallardo and Sabine Ulamec for their help obtaining EM micrographs. We thank all our group members, especially those in the "amyloid team", for many helpful discussions.

\section{REFERENCES}

(1) Pieters, B. J. G. E.; van Eldijk, M. B.; Nolte, R. J. M.; Mecinović, J. Natural supramolecular protein assemblies. Chem. Soc. Rev. 2016, $45,24-39$.

(2) Garcia-Seisdedos, H.; Villegas, J. A.; Levy, E. D. Infinite assembly of folded proteins in evolution, disease, and engineering. Angew. Chem., Int. Ed. 2019, 58, 5514-5531.

(3) Novo, M.; Freire, S.; Al-Soufi, W. Critical aggregation concentration for the formation of early amyloid- $\beta(1-42)$ oligomers. Sci. Rep. 2018, 8, 1783.

(4) Owen, M. C.; Gnutt, D.; Gao, M.; Wärmländer, S. K. T. S.; Jarvet, J.; Gräslund, A.; Winter, R.; Ebbinghaus, S.; Strodel, B. Effects of in vivo conditions on amyloid aggregation. Chem. Soc. Rev. 2019, 48, 3946-3996.

(5) Stephens, A. D.; Zacharopoulou, M.; Kaminski Schierle, G. S. The cellular environment affects monomeric $\alpha$-synuclein structure. Trends Biochem. Sci. 2019, 44, 453-466.

(6) Rodriguez Camargo, D. C.; Tripsianes, K.; Buday, K.; Franko, A.; Göbl, C.; Hartlmüller, C.; Sarkar, R.; Aichler, M.; Mettenleiter, G.; Schulz, M.; Böddrich, A.; Erck, C.; Martens, H.; Walch, A. K.; Madl, T.; Wanker, E. E.; Conrad, M.; Hrabě de Angelis, M.; Reif, B. The redox environment triggers conformational changes and aggregation of hIAPP in type II diabetes. Sci. Rep. 2017, 7, 44041.

(7) Garcia-Seisdedos, H.; Empereur-Mot, C.; Elad, N.; Levy, E. D. Proteins evolve on the edge of supramolecular self-assembly. Nature 2017, 548, 244-247.

(8) De Baets, G.; Van Doorn, L.; Rousseau, F.; Schymkowitz, J. Increased aggregation is more frequently associated to human diseaseassociated mutations than to neutral polymorphisms. PLoS Comput. Biol. 2015, 11, e1004374.

(9) Park, S.; Lee, J. H.; Jeon, J. H.; Lee, M. J. Degradation or aggregation: the ramifications of post-translational modifications on tau. BMB Rep. 2018, 51, 265-273.

(10) Barykin, E. P.; Mitkevich, V. A.; Kozin, S. A.; Makarov, A. A. Amyloid $\beta$ modification: a key to the sporadic Alzheimer's disease? Front. Genet. 2017, 8, 58. 
(11) Sambataro, F.; Pennuto, M. Post-translational modifications and protein quality control in motor neuron and polyglutamine diseases. Front. Mol. Neurosci. 2017, 10, 82.

(12) Eaton, W. A.; Hofrichter, J. Sickle cell hemoglobin polymerization. Adv. Protein Chem. 1990, 40, 63-279.

(13) Chiti, F.; Dobson, C. M. Protein misfolding, amyloid formation, and human disease: a summary of progress over the last decade. Annu. Rev. Biochem. 2017, 86, 27-68.

(14) Iadanza, M. G.; Jackson, M. P.; Hewitt, E. W.; Ranson, N. A.; Radford, S. E. A new era for understanding amyloid structures and disease. Nat. Rev. Mol. Cell Biol. 2018, 19, 755-773.

(15) Kumar, S.; Henning-Knechtel, A.; Magzoub, M.; Hamilton, A. D. Peptidomimetic-based multidomain targeting offers critical evaluation of $\mathrm{A} \beta$ structure and toxic function. J. Am. Chem. Soc. 2018, 140, 6562-6574.

(16) Hoffmann, W.; Folmert, K.; Moschner, J.; Huang, X.; von Berlepsch, H.; Koksch, B.; Bowers, M. T.; von Helden, G.; Pagel, K. NFGAIL amyloid oligomers: the onset of beta-sheet formation and the mechanism for fibril formation. J. Am. Chem. Soc. 2018, 140, 244249.

(17) Economou, N. J.; Giammona, M. J.; Do, T. D.; Zheng, X.; Teplow, D. B.; Buratto, S. K.; Bowers, M. T. Amyloid $\beta$-protein assembly and Alzheimer's disease: dodecamers of $A \beta 42$, but not of A $\beta 40$, seed fibril formation. J. Am. Chem. Soc. 2016, 138, 1772-1775.

(18) Hsieh, M.-C.; Liang, C.; Mehta, A. K.; Lynn, D. G.; Grover, M. A. Multistep conformation selection in amyloid assembly. J. Am. Chem. Soc. 2017, 139, 17007-17010.

(19) Salveson, P. J.; Haerianardakani, S.; Thuy-Boun, A.; Kreutzer, A. G.; Nowick, J. S. Controlling the oligomerization state of $\mathrm{A} \beta$ derived peptides with light. J. Am. Chem. Soc. 2018, 140, 5842-5852.

(20) Mondal, S.; Jacoby, G.; Sawaya, M. R.; Arnon, Z. A.; AdlerAbramovich, L.; Rehak, P.; Vuković, L.; Shimon, L. J. W.; Král, P.; Beck, R.; Gazit, E. Transition of metastable cross- $\alpha$ crystals into cross$\beta$ fibrils by $\beta$-turn flipping. J. Am. Chem. Soc. 2019, 141, 363-369.

(21) Eisele, Y. S.; Monteiro, C.; Fearns, C.; Encalada, S. E.; Wiseman, R. L.; Powers, E. T.; Kelly, J. W. Targeting protein aggregation for the treatment of degenerative diseases. Nat. Rev. Drug Discovery 2015, 14, 759-780.

(22) Seroski, D. T.; Hudalla, G. A. Self-assembled peptide and protein nanofibers for biomedical applications. In Biomedical Applications of Functionalized Nanomaterials: Concepts, Development and Clinical Translation; Elsevier Inc.: Amsterdam, 2018; pp 569598.

(23) Adler-Abramovich, L.; Gazit, E. The physical properties of supramolecular peptide assemblies: from building block association to technological applications. Chem. Soc. Rev. 2014, 43, 6881-6893.

(24) Breydo, L.; Uversky, V. N. Structural, morphological, and functional diversity of amyloid oligomers. FEBS Lett. 2015, 589, $2640-2648$.

(25) Kjaergaard, M.; Dear, A. J.; Kundel, F.; Qamar, S.; Meisl, G.; Knowles, T. P. J.; Klenerman, D. Oligomer diversity during the aggregation of the repeat region of tau. ACS Chem. Neurosci. 2018, 9, $3060-3071$

(26) Wilson, C. G.; Arkin, M. R. Probing structural adaptivity at PPI interfaces with small molecules. Drug Discovery Today: Technol. 2013, 10, e501-e 508.

(27) Krall, N.; da Cruz, F. P.; Boutureira, O.; Bernardes, G. J. L. Siteselective protein-modification chemistry for basic biology and drug development. Nat. Chem. 2016, 8, 103-113.

(28) Wright, T. H.; Bower, B. J.; Chalker, J. M.; Bernardes, G. J. L.; Wiewiora, R.; Ng, W. L.; Raj, R.; Faulkner, S.; Vallée, M. R. J.; Phanumartwiwath, A.; Coleman, O. D.; Thézénas, M.-L.; Khan, M.; Galan, S. R. G.; Lercher, L.; Schombs, M. W.; Gerstberger, S.; PalmEspling, M. E.; Baldwin, A. J.; Kessler, B. M.; Claridge, T. D. W.; Mohammed, S.; Davis, B. G. Posttranslational mutagenesis: a chemical strategy for exploring protein side-chain diversity. Science 2016, 354, aag1465.

(29) van Hateren, A.; Bailey, A.; Elliott, T. Recent advances in Major Histocompatibility Complex (MHC) class I antigen presentation: plastic MHC molecules and TAPBPR-mediated quality control. F1000Research 2017, 6, 158 .

(30) Iadanza, M. G.; Silvers, R.; Boardman, J.; Smith, H. I.; Karamanos, T. K.; Debelouchina, G. T.; Su, Y.; Griffin, R. G.; Ranson, N. A.; Radford, S. E. The structure of a $\beta 2$-microglobulin fibril suggests a molecular basis for its amyloid polymorphism. Nat. Commun. 2018, 9, 4517.

(31) Eichner, T.; Radford, S. E. Understanding the complex mechanisms of $\beta 2$-microglobulin amyloid assembly. FEBS J. 2011, $278,3868-3883$.

(32) Scarpioni, R.; Ricardi, M.; Albertazzi, V.; De Amicis, S.; Rastelli, F.; Zerbini, L. Dialysis-related amyloidosis: challenges and solutions. Int. J. Nephrol. Renovasc. Dis. 2016, 9, 319-328.

(33) Gejyo, F.; Yamada, T.; Odani, S.; Nakagawa, Y.; Arakawa, M.; Kunitomo, T.; Kataoka, H.; Suzuki, M.; Hirasawa, Y.; Shirahama, T.; Cohen, A. S.; Schmid, K. A new form of amyloid protein associated with chronic hemodialysis was identified as $\beta 2$-microglobulin. Biochem. Biophys. Res. Commun. 1985, 129, 701-706.

(34) Bellotti, V.; Stoppini, M.; Mangione, P.; Sunde, M.; Robinson, C.; Asti, L.; Brancaccio, D.; Ferri, G. B2-microglobulin can be refolded into a native state from ex vivo amyloid fibrils. Eur. J. Biochem. 1998, 258, 61-67.

(35) Stoppini, M.; Arcidiaco, P.; Mangione, P.; Giorgetti, S.; Brancaccio, D.; Bellotti, V. Detection of fragments of $\beta 2$-microglobulin in amyloid fibrils. Kidney Int. 2000, 57, 349-350.

(36) Eichner, T.; Kalverda, A. P.; Thompson, G. S.; Homans, S. W.; Radford, S. E. Conformational conversion during amyloid formation at atomic resolution. Mol. Cell 2011, 41, 161-172.

(37) Karamanos, T. K.; Jackson, M. P.; Calabrese, A. N.; Goodchild, S. C.; Cawood, E. E.; Thompson, G. S.; Kalverda, A. P.; Hewitt, E. W.; Radford, S. E. Structural mapping of oligomeric intermediates in an amyloid assembly pathway. eLife $\mathbf{2 0 1 9}, 8$, e46574.

(38) Su, Y.; Sarell, C. J.; Eddy, M. T.; Debelouchina, G. T.; Andreas, L. B.; Pashley, C. L.; Radford, S. E.; Griffin, R. G. Secondary structure in the core of amyloid fibrils formed from human $\beta 2 \mathrm{~m}$ and its truncated variant $\Delta$ N6. J. Am. Chem. Soc. 2014, 136, 6313-6325.

(39) Hall, Z.; Schmidt, C.; Politis, A. Uncovering the early assembly mechanism for amyloidogenic $\beta 2$-microglobulin using cross-linking and native mass spectrometry. J. Biol. Chem. 2016, 291, 4626-4637.

(40) Karamanos, T. K.; Kalverda, A. P.; Thompson, G. S.; Radford, S. E. Visualization of transient protein-protein interactions that promote or inhibit amyloid assembly. Mol. Cell 2014, 55, 214-226.

(41) Rennella, E.; Cutuil, T.; Schanda, P.; Ayala, I.; Gabel, F.; Forge, V.; Corazza, A.; Esposito, G.; Brutscher, B. Oligomeric states along the folding pathways of $\beta 2$-microglobulin: kinetics, thermodynamics, and structure. J. Mol. Biol. 2013, 425, 2722-2736.

(42) Domanska, K.; Vanderhaegen, S.; Srinivasan, V.; Pardon, E.; Dupeux, F.; Marquez, J. A.; Giorgetti, S.; Stoppini, M.; Wyns, L.; Bellotti, V.; Steyaert, J. Atomic structure of a nanobody-trapped domain-swapped dimer of an amyloidogenic $\beta 2$-microglobulin variant. Proc. Natl. Acad. Sci. U. S. A. 2011, 108, 1314-1319.

(43) Wang, N.; Majmudar, C. Y.; Pomerantz, W. C.; Gagnon, J. K.; Sadowsky, J. D.; Meagher, J. L.; Johnson, T. K.; Stuckey, J. A.; Brooks, C. L., III; Wells, J. A.; Mapp, A. K. Ordering a dynamic protein via a small molecule stabilizer. J. Am. Chem. Soc. 2013, 135, 3363-3366.

(44) Sijbesma, E.; Hallenbeck, K. K.; Leysen, S.; de Vink, P. J.; Skóra, L.; Jahnke, W.; Brunsveld, L.; Arkin, M. R.; Ottmann, C. Sitedirected fragment-based screening for the discovery of protein-protein interaction stabilizers. J. Am. Chem. Soc. 2019, 141, 3524-3531.

(45) Lee, S.; Wales, T. E.; Escudero, S.; Cohen, D. T.; Luccarelli, J.; Gallagher, C. G.; Cohen, N. A.; Huhn, A. J.; Bird, G. H.; Engen, J. R.; Walensky, L. D. Allosteric inhibition of antiapoptotic MCL-1. Nat. Struct. Mol. Biol. 2016, 23, 600-607.

(46) Kozakov, D.; Grove, L. E.; Hall, D. R.; Bohnuud, T.; Mottarella, S. E.; Luo, L.; Xia, B.; Beglov, D.; Vajda, S. The FTMap family of web servers for determining and characterizing ligand-binding hot spots of proteins. Nat. Protoc. 2015, 10, 733-755. 
(47) Erlanson, D. A.; Braisted, A. C.; Raphael, D. R.; Randal, M.; Stroud, R. M.; Gordon, E. M.; Wells, J. A. Site-directed ligand discovery. Proc. Natl. Acad. Sci. U. S. A. 2000, 97, 9367-9372.

(48) Goktug, A. N.; Chai, S. C.; Chen, T. Data analysis approaches in high throughput screening. In Drug Discovery; IntechOpen: 2013; pp 201-226.

(49) Svedberg, T.; Pedersen, K. O. The Ultracentrifuge; Oxford University Press: Oxford, U.K., 1940.

(50) Xue, C.; Lin, T. Y.; Chang, D.; Guo, Z. Thioflavin T as an amyloid dye: fibril quantification, optimal concentration and effect on aggregation. R. Soc. Open Sci. 2017, 4, 160696.

(51) Biancalana, M.; Koide, S. Molecular mechanism of Thioflavin-T binding to amyloid fibrils. Biochim. Biophys. Acta, Proteins Proteomics 2010, 1804, 1405-1412.

(52) Hall, D.; Zhao, R.; So, M.; Adachi, M.; Rivas, G.; Carver, J. A.; Goto, Y. Recognizing and analyzing variability in amyloid formation kinetics: Simulation and statistical methods. Anal. Biochem. 2016, 510, $56-71$.

(53) Eakin, C. M.; Berman, A. J.; Miranker, A. D. A native to amyloidogenic transition regulated by a backbone trigger. Nat. Struct. Mol. Biol. 2006, 13, 202-208.

(54) Calabrese, M. F.; Eakin, C. M.; Wang, J. M.; Miranker, A. D. A regulatable switch mediates self-association in an immunoglobulin fold. Nat. Struct. Mol. Biol. 2008, 15, 965-971.

(55) Colombo, M.; De Rosa, M.; Bellotti, V.; Ricagno, S.; Bolognesi, M. A recurrent $\mathrm{D}$-strand association interface is observed in $\beta$-2 microglobulin oligomers. FEBS J. 2012, 279, 1131-1143.

(56) Halabelian, L.; Relini, A.; Barbiroli, A.; Penco, A.; Bolognesi, M.; Ricagno, S. A covalent homodimer probing early oligomers along amyloid aggregation. Sci. Rep. 2015, 5, 14651.

(57) Blaho, D. V.; Miranker, A. D. Delineating the conformational elements responsible for $\mathrm{Cu} 2+$-induced oligomerization of $\beta$-2 microglobulin. Biochemistry 2009, 48, 6610-6617.

(58) Wang, N.; Lodge, J. M.; Fierke, C. A.; Mapp, A. K. Dissecting allosteric effects of activator-coactivator complexes using a covalent small molecule ligand. Proc. Natl. Acad. Sci. U. S. A. 2014, 111, 12061-12066.

(59) Ruiz, J.; Boehringer, R.; Grogg, M.; Raya, J.; Schirer, A.; Crucifix, C.; Hellwig, P.; Schultz, P.; Torbeev, V. Covalent tethering and residues with bulky hydrophobic side chains enable self-assembly of distinct amyloid structures. ChemBioChem 2016, 17, 2274-2285.

(60) Cardoso, R.; Love, R.; Nilsson, C. L.; Bergqvist, S.; Nowlin, D.; Yan, J.; Liu, K. K.-C.; Zhu, J.; Chen, P.; Deng, Y.-L.; Dyson, H. J.; Greig, M. J.; Brooun, A. Identification of Cys 255 in HIF- $1 \alpha$ as a novel site for development of covalent inhibitors of HIF-1 $\alpha /$ ARNT PasB domain protein-protein interaction. Protein Sci. 2012, 21, 1885-1896.

(61) Backus, K. M.; Correia, B. E.; Lum, K. M.; Forli, S.; Horning, B. D.; González-Páez, G. E.; Chatterjee, S.; Lanning, B. R.; Teijaro, J. R.; Olson, A. J.; Wolan, D. W.; Cravatt, B. F. Proteome-wide covalent ligand discovery in native biological systems. Nature 2016, 534, 570574.

(62) Sadowsky, J. D.; Burlingame, M. A.; Wolan, D. W.; McClendon, C. L.; Jacobson, M. P.; Wells, J. A. Turning a protein kinase on or off from a single allosteric site via disulfide trapping. Proc. Natl. Acad. Sci. U. S. A. 2011, 108, 6056-6061.

(63) Ostrem, J. M.; Peters, U.; Sos, M. L.; Wells, J. A.; Shokat, K. M. K-Ras(G12C) inhibitors allosterically control GTP affinity and effector interactions. Nature 2013, 503, 548-551.

(64) Weichert, D.; Kruse, A. C.; Manglik, A.; Hiller, C.; Zhang, C.; Hübner, H.; Kobilka, B. K.; Gmeiner, P. Covalent agonists for studying G protein-coupled receptor activation. Proc. Natl. Acad. Sci. U. S. A. 2014, 111, 10744-10748.

(65) Krishnamurthy, V. M.; Semetey, V.; Bracher, P. J.; Shen, N.; Whitesides, G. M. Dependence of effective molarity on linker length for an intramolecular protein-ligand system. J. Am. Chem. Soc. 2007, 129, 1312-1320.

(66) Zhou, H.-X. Quantitative relation between intermolecular and intramolecular binding of Pro-rich peptides to $\mathrm{SH} 3$ domains. Biophys. J. 2006, 91, 3170-3181.
(67) Young, L. M.; Ashcroft, A. E.; Radford, S. E. Small molecule probes of protein aggregation. Curr. Opin. Chem. Biol. 2017, 39, 9099.

(68) Miles, J. A.; Yeo, D. J.; Rowell, P.; Rodriguez-Marin, S.; Pask, C. M.; Warriner, S. L.; Edwards, T. A.; Wilson, A. J. Hydrocarbon constrained peptides - understanding preorganisation and binding affinity. Chem. Sci. 2016, 7, 3694-3702.

(69) Chung, N.; Zhang, X. D.; Kreamer, A.; Locco, L.; Kuan, P. F.; Bartz, S.; Linsley, P. S.; Ferrer, M.; Strulovici, B. Median absolute deviation to improve hit selection for genome-scale RNAi screens. J. Biomol. Screening 2008, 13, 149-158.

(70) Schuck, P. Size-distribution analysis of macromolecules by sedimentation velocity ultracentrifugation and Lamm equation modeling. Biophys. J. 2000, 78, 1606-1619.

(71) Hurton, T.; Wright, A.; Deubler, G.; Bashir, B. SEDNTERP. 2012. http://bitc.unh.edu.

(72) Brown, P. H.; Balbo, A.; Schuck, P. Using prior knowledge in the determination of macromolecular size-distributions by analytical ultracentrifugation. Biomacromolecules 2007, 8, 2011-2024.

(73) Smith, P. K.; Krohn, R. I.; Hermanson, G. T.; Mallia, A. K.; Gartner, F. H.; Provenzano, M. D.; Fujimoto, E. K.; Goeke, N. M.; Olson, B. J.; Klenk, D. C. Measurement of protein using bicinchroninic acid. Anal. Biochem. 1985, 150, 76-85.

(74) Winter, G. Xia2: An expert system for macromolecular crystallography data reduction. J. Appl. Crystallogr. 2010, 43, 186190.

(75) Winter, G.; Waterman, D. G.; Parkhurst, J. M.; Brewster, A. S.; Gildea, R. J.; Gerstel, M.; Fuentes-Montero, L.; Vollmar, M.; MichelsClark, T.; Young, I. D.; Sauter, N. K.; Evans, G. DIALS: implementation and evaluation of a new integration package. Acta Crystallogr. Sect. D Struct. Biol. 2018, 74, 85-97.

(76) Evans, P. Scaling and assessment of data quality. Acta Crystallogr., Sect. D: Biol. Crystallogr. 2006, 62, 72-82.

(77) Evans, P. R.; Murshudov, G. N. How good are my data and what is the resolution? Acta Crystallogr., Sect. D: Biol. Crystallogr. 2013, 69, 1204-1214.

(78) Karplus, P. A.; Diederichs, K. Linking Crystallographic Model and Data Quality. Science 2012, 336, 1030-1033.

(79) Le Marchand, T.; de Rosa, M.; Salvi, N.; Sala, B. M.; Andreas, L. B.; Barbet-Massin, E.; Sormanni, P.; Barbiroli, A.; Porcari, R.; Mota, C. S.; de Sanctis, D.; Bolognesi, M.; Emsley, L.; Bellotti, V.; Blackledge, M.; Camilloni, C.; Pintacuda, G.; Ricagno, S. Conformational dynamics in crystals reveal the molecular bases for $\mathrm{D} 76 \mathrm{~N}$ beta- 2 microglobulin aggregation propensity. Nat. Commun. 2018, 9, 1658.

(80) McCoy, A. J.; Grosse-Kunstleve, R. W.; Adams, P. D.; Winn, M. D.; Storoni, L. C.; Read, R. J. Phaser crystallographic software. J. Appl. Crystallogr. 2007, 40, 658-674.

(81) Emsley, P.; Lohkamp, B.; Scott, W. G.; Cowtan, K. Features and development of Coot. Acta Crystallogr., Sect. D: Biol. Crystallogr. 2010, 66, 486-501.

(82) Murshudov, G. N.; Skubák, P.; Lebedev, A. A.; Pannu, N. S.; Steiner, R. A.; Nicholls, R. A.; Winn, M. D.; Long, F.; Vagin, A. A. REFMAC5 for the refinement of macromolecular crystal structures. Acta Crystallogr., Sect. D: Biol. Crystallogr. 2011, 67, 355-367.

(83) Schwieters, C. D.; Bermejo, G. A.; Clore, G. M. Xplor-NIH for molecular structure determination from NMR and other data sources. Protein Sci. 2018, 27, 26-40.

(84) Chen, V. B.; Arendall, W. B.; Headd, J. J.; Keedy, D. A.; Immormino, R. M.; Kapral, G. J.; Murray, L. W.; Richardson, J. S.; Richardson, D. C. MolProbity: all-atom structure validation for macromolecular crystallography. Acta Crystallogr., Sect. D: Biol. Crystallogr. 2010, 66, 12-21.

(85) Delaglio, F.; Grzesiek, S.; Vuister, G. W.; Zhu, G.; Pfeifer, J.; Bax, A. NMRPipe: a multidimensional spectral processing system based on UNIX pipes. J. Biomol. NMR 1995, 6, 277-293.

(86) Vranken, W. F.; Boucher, W.; Stevens, T. J.; Fogh, R. H.; Pajon, A.; Llinas, M.; Ulrich, E. L.; Markley, J. L.; Ionides, J.; Laue, E. D. The CCPN data model for NMR spectroscopy: development of a software pipeline. Proteins: Struct., Funct., Genet. 2005, 59, 687-696. 